\title{
Pyrethroid pesticides as endocrine disruptors: molecular mechanisms in vertebrates with a
} focus on fishes

\author{
Susanne M. Brander*\#, Molly K. Gabler", Nicholas L. Fowler ${ }^{\#}$, Richard E. Connon ${ }^{\S}$, Daniel \\ Schlenk \\ ${ }^{\#}$ Biology \& Marine Biology, University of North Carolina at Wilmington, 601 South College \\ Road, Wilmington, North Carolina, 28403. \\ Environmental Sciences, College of Natural and Agricultural Sciences, University of California \\ at Riverside, 900 University Avenue, Riverside, California, 92521. \\ §Anatomy, Physiology \& Cell Biology, School of Veterinary Medicine, University of California \\ at Davis, One Shields Avenue, Davis, California, 95616. \\ *branders@uncw.edu
}

One figure: Figure S1.

Figure S1: a) figure demonstrating that the two chiral centers of the pyrethroid bifenthrin allow for two enantiomeric forms, 1R-cis and 1S-cis.; b) table summarizing pyrethroid endocrine effects per test type (fish, mammal, in vitro) and concentration. 
a)

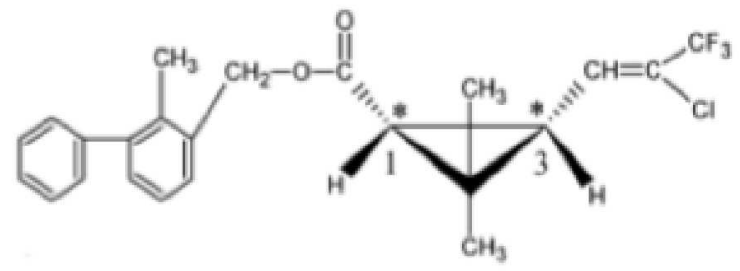

1R-cis-Bifenthrin

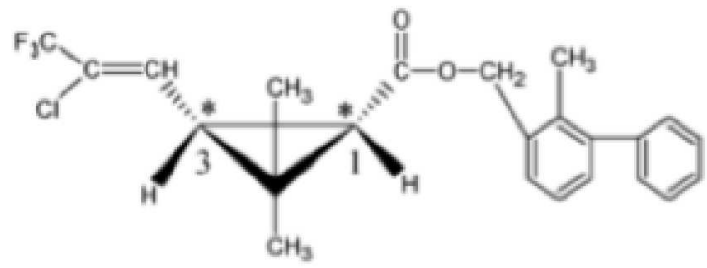

1S-cis-Bifenthrin 
b)

\begin{tabular}{|c|c|c|c|}
\hline Pesticide & Concentration & Endocrine Effect & Reference \\
\hline \multicolumn{4}{|l|}{ Permethrin } \\
\hline \multirow{8}{*}{ Fish } & $10 \mu \mathrm{g} / \mathrm{L}$ & $\begin{array}{l}\text { 1S-cis and 1-trans permethrin: } \\
\text { caused vitellogenin production } \\
\text { (estrogenic) }\end{array}$ & Nillos et al., 2010 \\
\hline & $250-500 \mathrm{ng} / \mathrm{L}$ & $\begin{array}{l}\text { Racemic permethrin: induction } \\
\text { of Vtg } 1 \text { gene expression }\end{array}$ & Jin et al., 2008 \\
\hline & $250-500 \mathrm{ng} / \mathrm{L}$ & $\begin{array}{l}\text { (-)Trans permethrin and (+) } \\
\text { trans permethrin: induction of } \\
\text { Vtg1 and Vtg2 gene expression, } \\
\text { greater after (-) trans exposure. }\end{array}$ & Jin et al., 2008 \\
\hline & $250-500 \mathrm{ng} / \mathrm{L}$ & $\begin{array}{l}\text { (-) Cis permethrin and (+) cis } \\
\text { permethrin: induction of Vtg1 } \\
\text { and Vtg } 2 \text { gene expression }\end{array}$ & Jin et al., 2008 \\
\hline & $250-1000 \mathrm{ng} / \mathrm{L}$ & $\begin{array}{l}\text { Racemic permethrin: induced } \\
\text { gene expression of Vtg1, Vtg2, } \\
\text { ESR } \alpha, \text { Cyp19a, Cyp19b }\end{array}$ & Jin et al., 2009 \\
\hline & $250,1000 \mathrm{ng} / \mathrm{L}$ & $\begin{array}{l}\text { (-) Cis permethrin and (+) cis } \\
\text { permethrin: induction of Vtg1, } \\
\text { ESR } \alpha, \text { Cyp } 19 \text { b gene expression, } \\
\text { different effects of }(-) \text { and }(+) \\
\text { cis exposures. }\end{array}$ & Jin et al., 2009 \\
\hline & $250,1000 \mathrm{ng} / \mathrm{L}$ & $\begin{array}{l}\text { (-)Trans permethrin and (+) } \\
\text { trans permethrin: induction of } \\
\text { Vtg1, ESR } \alpha, \text { Cyp19a, Cyp19b } \\
\text { gene expression, greater after (-) } \\
\text { trans exposure. }\end{array}$ & Jin et al., 2009 \\
\hline & $0.1-10 \mu \mathrm{g} / \mathrm{L}$ & $\begin{array}{l}\text { Permethrin }(50 / 50 \text { isomer mix }) \text { : } \\
\text { induced choriogenin protein } \\
\text { expression }\end{array}$ & Brander et al., 2012 \\
\hline \multirow{2}{*}{ Mammals } & $70 \mathrm{mg} / \mathrm{kg} /$ day & $\begin{array}{l}\text { Cis permethrin: sperm count and } \\
\text { motility reduced, T levels } \\
\text { reduced, abnormal seminiferous } \\
\text { tubules, suppressed gene } \\
\text { expression (StAR, P450 SCC) }\end{array}$ & Zhang et al., 2008 \\
\hline & $70 \mathrm{mg} / \mathrm{kg} /$ day & $\begin{array}{l}\text { Trans permethrin: no adverse } \\
\text { effects, 3-PBA levels } 3 \text {-7fold } \\
\text { higher than with cis permethrin }\end{array}$ & Zhang et al., 2008 \\
\hline \multirow{5}{*}{ In vitro } & $10^{-7}-10^{-4} \mathrm{M}$ & $\begin{array}{l}\text { Trans permethrin: anti- } \\
\text { androgenic, weakly estrogenic }\end{array}$ & Tange et al., 2014 \\
\hline & $10^{-7}-10^{-4} \mathrm{M}$ & $\begin{array}{l}\text { Cis permethrin: weakly anti- } \\
\text { androgenic, weakly estrogenic }\end{array}$ & Tange et al., 2014 \\
\hline & $10^{-7}-10^{-4} \mathrm{M}$ & 4'-OH PBAIc: estrogenic & Tange et al., 2014 \\
\hline & $10^{-7}-10^{-4} \mathrm{M}$ & $\begin{array}{l}\text { PBAIc: estrogenic and anti- } \\
\text { androgenic }\end{array}$ & Tange et al., 2014 \\
\hline & $10^{-7}-10^{-4} \mathrm{M}$ & PBAId: anti-androgenic & Tange et al., 2014 \\
\hline
\end{tabular}




\begin{tabular}{|c|c|c|c|}
\hline & $10^{-7}-10^{-4} \mathrm{M}$ & $\begin{array}{l}\text { 4'-OH cis permethrin: } \\
\text { estrogenic and anti-androgenic }\end{array}$ & Tange et al., 2014 \\
\hline & $\begin{array}{l}5,10,25,50,100 \\
\square \mathrm{M}\end{array}$ & $\begin{array}{l}\text { Increased in vitro vitellogenin } \\
\text { production in fish hepatocytes } \\
\text { (estrogenic) }\end{array}$ & Nillos et al., 2010 \\
\hline & $10^{-4}-10^{-3} \mathrm{M}$ & $\begin{array}{l}\text { Estrogenic activity on } \mathrm{hER}_{\alpha} \text { and } \\
\mathrm{rER}_{\alpha} \text { subtypes of } \mathrm{CV}-1 \text { cells }\end{array}$ & Sun et al., 2014 \\
\hline & $10^{-8}-10^{-6} \mathrm{M}$ & $\begin{array}{l}\text { Estrogenic in MCF- } 7 \text { assay, } \\
\text { altered ps } 2 \text { and ER } \alpha \text { expression }\end{array}$ & Jin et al., 2010 \\
\hline & $10^{-7}-10^{-6}$ & $\begin{array}{l}\text { Estrogenic in MCF-7 assay, ER } \\
\text { binding inhibition, induced ps } 2 \\
\text { gene expression }\end{array}$ & Chen et al., 2002 \\
\hline & $0.43 \mathrm{mM}$ & $\begin{array}{l}\text { Antiandrogenic in AR-mediated } \\
\text { reporter gene assay (CV-1 cells) }\end{array}$ & Sun et al., 2007 \\
\hline & $81.38 \mu \mathrm{M}$ & $\begin{array}{l}\text { Estrogenic in } \mathrm{rER}_{\alpha} \text { subtype of } \\
\mathrm{CV}-1\end{array}$ & Sun et al., 2014 \\
\hline & $84 \mu \mathrm{M}$ & Estrogenic in $\mathrm{hER}_{\alpha}(\mathrm{CHO}$ cells $)$ & Kojima et al., 2004 \\
\hline & $8.1 \times 10^{-7} \mathrm{M}$ & Estrogenic in $\mathrm{ER}_{\alpha}(\mathrm{CV}-1$ cells $)$ & Du et al., 2010 \\
\hline & $>10^{-5} \mathrm{M}$ & $\begin{array}{l}\text { Anti-estrogenic in } \mathrm{ER}_{\alpha}(\mathrm{CV}-1 \\
\text { cells })\end{array}$ & Du et al., 2010 \\
\hline & $1.88 \times 10^{-6} \mathrm{M}$ & $\begin{array}{l}\text { Anti-androgenic in MDA-kb2 } \\
\text { cells }\end{array}$ & Du et al., 2010 \\
\hline & $1.50 \times 10^{-9} \mathrm{M}$ & $\begin{array}{l}\text { Antagonism in } \mathrm{TR}_{\beta}(\mathrm{CV}-1 \\
\text { cells) }\end{array}$ & Du et al., 2010 \\
\hline & $10^{-6} \mathrm{M}$ & $\begin{array}{l}\text { Anti-estrogenic in MCF-7 BUS } \\
\text { cells }\end{array}$ & Kim et al., 2004 \\
\hline & $100 \mu \mathrm{M}$ & $\begin{array}{l}\text { Induced cell proliferation and } \\
\text { ps } 2 \text { expression in MCF-7 cells }\end{array}$ & Go et al., 1999 \\
\hline & $0.1-1000 \mu \mathrm{g} / \mathrm{L}$ & Anti-estrogenic in ER CALUX & Brander et al., 2012 \\
\hline & $10^{-3}-10^{-4}$ & Estrogenic in yeast hER & Tyler et al., 2000 \\
\hline & $10^{-4}-10^{-5}$ & Anti-androgenic in yeast hAR & Tyler et al., 2000 \\
\hline & $4-64 \mu \mathrm{M}$ & $\begin{array}{l}\text { Decrease in rat sperm motility } \\
\text { parameters (e.g. velocity, } \\
\text { linearity) }\end{array}$ & Yuan et al., 2010 \\
\hline Bifer & & & \\
\hline & $10 \mathrm{ng} / \mathrm{L}$ & $\begin{array}{l}\text { 4'-OH bifenthrin: estrogenic - } \\
\text { induced choriogenin protein }\end{array}$ & $\begin{array}{l}\text { DeGroot and } \\
\text { Brander, } 2014\end{array}$ \\
\hline & $10 \mathrm{ng} / \mathrm{L}$ & $\begin{array}{l}\text { P450 inhibitor eliminated } \\
\text { choriogenin production (not } \\
\text { estrogenic) }\end{array}$ & $\begin{array}{l}\text { DeGroot and } \\
\text { Brander, } 2014\end{array}$ \\
\hline Fish & $0.07-0.35 \mu \mathrm{g} / \mathrm{L}$ & $\begin{array}{l}\text { Altered expression of transcripts } \\
\text { involved in endocrine } \\
\text { regulation, growth, nerve repair, } \\
\text { muscular function, energetic } \\
\text { status }\end{array}$ & Beggel et al., 2011 \\
\hline & $10 \mathrm{ng} / \mathrm{mL}$ & $\begin{array}{l}\text { Vitellogenin protein induced, } 1 S \\
\text { cis bifenthrin } 123 \mathrm{x} \text { greater than } \\
\text { IR cis bifenthrin }\end{array}$ & Wang et al., 2007 \\
\hline & $150 \mu \mathrm{g} / \mathrm{L}$ & Induced Vtg1 gene expression & Jin et al., 2009 \\
\hline
\end{tabular}




\begin{tabular}{|c|c|c|c|}
\hline & $1-100 \mathrm{ng} / \mathrm{L}$ & $\begin{array}{l}\text { Induced choriogenin protein, } \\
\text { highest at } 1 \mathrm{ng} / \mathrm{L} 133 \text { ) }\end{array}$ & Brander et al., 2012 \\
\hline & $0.1,1.5 \mu \mathrm{g} / \mathrm{L}$ & $\begin{array}{l}\text { Freshwater: Lower male GSI, } \\
\text { increased female plasma E2 \& } \\
\text { ovarian follicle diameter; } \\
\text { Saltwater: reduced E2, smaller } \\
\text { unhealthy follicles }\end{array}$ & Forsgren et al., 2013 \\
\hline & $1.5 \mu \mathrm{g} / \mathrm{L}$ & $\begin{array}{l}\text { Increased plasma E2, increased } \\
\text { Vtg mRNA, decreased } \\
\text { dopamine receptor (DR2a) } \\
\text { mRNA, GnRH2 mRNA } \\
\text { increased then decreased } \\
\text { (feedback) }\end{array}$ & Crago et al., 2015 \\
\hline \multirow{3}{*}{ Mammals } & $15 \mathrm{mg} / \mathrm{kg}$ (maternal) & $\begin{array}{l}\text { 1S cis bifenthrin: decreased } \\
\text { cholesterol synthesis (gene } \\
\text { expression of HMG-CoA } \\
\text { synthase and reductase, LDL-R, } \\
\text { PBR, StAR, P450scc, } 3 \beta-H S D \text {, } \\
\text { P45017 } \alpha \text { decreased) in } 3 \& 6 \\
\text { week male rat offspring }\end{array}$ & Jin et al., 2013 \\
\hline & $15 \mathrm{mg} / \mathrm{kg}$ (maternal) & $\begin{array}{l}\text { 1S cis bifenthrin: decreased } \\
\text { cholesterol synthesis (gene } \\
\text { expression of HMG-CoA } \\
\text { synthase and reductase, LDL-R } \\
\text { decreased) in } 3 \& 6 \text { week male } \\
\text { rat offspring }\end{array}$ & Jin et al., 2013 \\
\hline & $0.5 \mathrm{mg} / \mathrm{rat}$ & $\begin{array}{l}\text { Decreased serum T3, T4, } \\
\text { increased TSH }\end{array}$ & Akhtar et al., 1996 \\
\hline \multirow{3}{*}{ In vitro } & $1-10,000 \mathrm{ng} / \mathrm{L}$ & $\begin{array}{l}\text { Anti-estrogenic in ER CALUX, } \\
\text { unimodal (antagonism greatest } \\
\text { at } 100 \mathrm{ng} / \mathrm{L} \text { ) }\end{array}$ & Brander et al., 2012 \\
\hline & $10^{-7}-10^{-5}$ & $\begin{array}{l}\text { 1S cis bifenthrin: Increased } \\
\text { production of progesterone and } \\
\text { hCG, increased gene exp. } \\
\text { CYP17, CYP19, 3 } \beta \text {-HSD, } \\
\text { GnRH, GnRHR, PR, HLA-G } \\
\text { decreased } 17 \beta-H S D(>1 R \text { or } \\
\text { racemic) in JEG-3 cells }\end{array}$ & Zhao et al., 2014 \\
\hline & $10^{-7}-10^{-5}$ & $\begin{array}{l}\text { lR cis bifenthrin: Increased } \\
\text { production of progesterone and } \\
\text { hCG, increased gene exp. } \\
\text { CYP17, CYP } 19,3 \beta-H S D \text {, } \\
\text { GnRH, GnRHR, PR, HLA-G in } \\
\text { JEG-3 cells }\end{array}$ & Zhao et al., 2014 \\
\hline
\end{tabular}




\begin{tabular}{|c|c|c|c|}
\hline & $10^{-7}-10^{-5}$ & 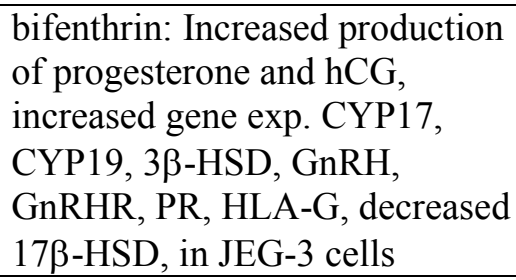 & Zhao et al., 2014 \\
\hline & $1-1000 \mathrm{nM}$ & $\begin{array}{l}\text { 1S cis bifenthrin: Disruption of } \\
\text { LH-induced ovulatory genes in } \\
\text { rat ovarian granulosa cells, } \\
\text { reduced prostaglandin E2 }\end{array}$ & Liu et al., 2011 \\
\hline & $10^{-9}-10^{-5}$ & $\begin{array}{l}1 S \text { cis bifenthrin: MCF- } 7 \text { cell } \\
\text { proliferation ( }>\text { than } 1 R \text { or } \text { cis } \\
\text { racemic mixture), increased ps } 2 \\
\text { expression }\end{array}$ & Zhao et al., 2010 \\
\hline & $10^{-9}-10^{-5}$ & $\begin{array}{l}1 R \text { cis bifenthrin: MCF-7 cell } \\
\text { proliferation, increased } \mathrm{ps} 2 \\
\text { expression }\end{array}$ & Zhao et al., 2010 \\
\hline & $10^{-9}-10^{-5}$ & $\begin{array}{l}\text { cis bifenthrin: MCF-7 cell } \\
\text { proliferation, increased ps } 2 \\
\text { expression }\end{array}$ & Zhao et al., 2010 \\
\hline & $10^{-9}$ & $\begin{array}{l}\text { 1S cis bifenthrin: estrogenic in } \\
\text { E-SCREEN assay, blocked by } \\
\text { ICI }\end{array}$ & Wang et al., 2007 \\
\hline & $10^{-8}$ & $\begin{array}{l}\text { IR cis bifenthrin: estrogenic in } \\
\text { E-SCREEN assay, blocked by } \\
\text { ICI }\end{array}$ & Wang et al., 2007 \\
\hline Cypermethrin & & & \\
\hline & $1.0 \mu \mathrm{g} / 1$ & $\begin{array}{l}\text { Decreased male's ability to } \\
\text { detect female priming } \\
\text { pheromones }\end{array}$ & Jaensson et al. 2007 \\
\hline Fish & $<0.004 \mu \mathrm{g} / 1$ & $\begin{array}{l}\text { Decrease male's response to } \\
\text { PGF } 2_{\alpha} \\
\text { Decrease fertilization rates of } \\
\text { eggs }\end{array}$ & $\begin{array}{l}\text { Moore and Waring } \\
2001\end{array}$ \\
\hline & 0.02 ppermethrin & $\begin{array}{l}\text { Deleterious effects on } \\
\text { gonadotrophic cells } \\
\text { Decreased sperm counts and } \\
\text { motility }\end{array}$ & $\begin{array}{l}\text { Singh and Singh } \\
2008\end{array}$ \\
\hline & $25 \mu \mathrm{g} / 1$ & $\begin{array}{l}\text { Embryo morphological } \\
\text { abnormalities }\end{array}$ & Shi et al. 2011 \\
\hline & 15 and $30 \mathrm{mg} / \mathrm{kg}$ & Decreased AR & Liu et al. 2010 \\
\hline & 1 and $20 \mathrm{mg} / \mathrm{kg}$ & $\begin{array}{l}\text { Decreased weight of testes, } \\
\text { epidydymides, seminal vesicles } \\
\text { and prostate }\end{array}$ & Wang et al. 2009 \\
\hline Mammals & $1.38 \mathrm{mg} / \mathrm{kg}$ & Decreased sperm count & $\begin{array}{l}\text { Al-Hamdani et al. } \\
2010\end{array}$ \\
\hline & $485 \mathrm{mg} / \mathrm{kg}$ & $\begin{array}{l}\text { Inflammation and mast cell } \\
\text { presence in seminal glands }\end{array}$ & Rodriguez et al. 2009 \\
\hline & $50 \mathrm{mg} / \mathrm{kg}$ & $\begin{array}{l}\text { Follicular atresia and decreased } \\
\text { follicular cells and oocytes }\end{array}$ & Sangha et al. 2013 \\
\hline
\end{tabular}




\begin{tabular}{|c|c|c|c|}
\hline \multirow{12}{*}{ In vitro } & $10^{-5} \mathrm{M}$ & $\begin{array}{l}\text { Inhibits interaction between AR } \\
\text { and N/C in CV-1 cells } \\
\text { ER agonist in CV-1, human } \\
\text { breast carcinoma MVLN cells } \\
\text { and hamster ovary CHO-K1 } \\
\text { cells } \\
\text { Induces estrogenic activity of } \\
\mathrm{hER}_{\alpha} \text { subtype in CHO-K1 cells } \\
\text { Enhances interaction between } \\
\mathrm{AR} \text { and corepressors }\end{array}$ & $\begin{array}{l}\text { Hu et al. 2013; } \\
\text { Kjeldsen et al. 2013; } \\
\text { Kojima et al. 2004; } \\
\text { Pan et al. 2012; Pan } \\
\text { et al. } 2013\end{array}$ \\
\hline & $30.82,4.01 \mu \mathrm{M}$ & $\begin{array}{l}\text { Estrogenic activity on } \mathrm{hER}_{\alpha} \text { and } \\
\mathrm{rER}_{\alpha} \text { subtypes of CV- } 1 \text { cells }\end{array}$ & Sun et al. 2014 \\
\hline & $64 \mu \mathrm{mol}$ & Inhibits sperm motility & Yuan et al. 2010 \\
\hline & 15 and $30 \mathrm{mg} / \mathrm{kg}$ & Spermatozoa head abnormalities & Liu et al. 2011 \\
\hline & $10^{-8}-10^{-6}$ & $\begin{array}{l}\text { Estrogenic in MCF-7 assay, } \\
\text { altered ps } 2 \text { and ER } \alpha \text { expression }\end{array}$ & Jin et al., 2010 \\
\hline & $0.42 \mathrm{mM}$ & $\begin{array}{l}\text { Anti-androgenic in AR- } \\
\text { mediated CV-1 reporter gene } \\
\text { assay }\end{array}$ & Sun et al., 2007 \\
\hline & $81 \mu \mathrm{M}$ & Estrogenic in $\mathrm{hER}_{\alpha}(\mathrm{CHO}$ line $)$ & Kojima et al., 2004 \\
\hline & $1.64 \times 10^{-6}$ & $\begin{array}{l}\text { Anti-androgenic in MDA-kb2 } \\
\text { cells }\end{array}$ & Du et al., 2010 \\
\hline & $8.31 \times 10^{-6}$ & Antagonism in $\mathrm{TR}_{\beta} \mathrm{CV}-1$ cells & Du et al., 2010 \\
\hline & $10^{-4}$ & Anti-estrogenic in yeast hER & Tyler et al., 2000 \\
\hline & $10^{-3}$ & Anti-androgenic in yeast hAR & Tyler et al., 2000 \\
\hline & $10^{-8}-10^{6}$ & $\begin{array}{l}\text { Estrogenic in MCF-7 assay, ER } \\
\text { binding inhibition, induced ps } 2 \\
\text { gene expression }\end{array}$ & Chen et al., 2002 \\
\hline \multicolumn{4}{|c|}{ Deltamethrin } \\
\hline \multirow{4}{*}{ Fish } & $1.5 \mathrm{mg} / \mathrm{kg}$ & $\begin{array}{l}\text { Decreased fecundity, hatching } \\
\text { rate and egg production }\end{array}$ & $\begin{array}{l}\text { Sharma and Ansari } \\
2010\end{array}$ \\
\hline & $0.1 \mathrm{ppb}$ & $\begin{array}{l}\text { Enhanced hypertrophy and } \\
\text { necrosis of hepatocytes and } \\
\text { altered hepatocyte distribution }\end{array}$ & Guardiola et al. 2014 \\
\hline & $0.75 \mu \mathrm{g} / 1$ & Oxidative stress & Sayeed et al. 2003 \\
\hline & 0.8 and $8.0 \mu \mathrm{l} / 1$ & $\begin{array}{l}\text { Decrease of } \mathrm{Na}^{2+}-\mathrm{K}^{+} \text {and } \mathrm{Mg}^{2+} \\
\mathrm{Ca}^{2+} \text { ATPase activity in the gill, } \\
\text { liver and muscle }\end{array}$ & David et al. 2014 \\
\hline Mammals & $3-6 \mathrm{mg} / \mathrm{kg}$ & $\begin{array}{l}\text { Reduced sperm count, motility } \\
\text { and viability, serum testosterone } \\
\text { level, sialic acid content of } \\
\text { caudal epididymis and fructose } \\
\text { level of seminal vesicle, } \\
\text { decreases in whole body and } \\
\text { organ weights, damaged } \\
\text { testicular histoarchitecture, } \\
\text { decline in the activity of } \\
\text { testicular } 3 b \text { and } 17 b\end{array}$ & Desai et al., 2016 \\
\hline
\end{tabular}




\begin{tabular}{|c|c|c|c|}
\hline & & $\begin{array}{l}\text { hydroxysteroid dehydrogenase } \\
\text { (HSD). }\end{array}$ & \\
\hline & $0.003 \mathrm{mg} / \mathrm{kg} / \mathrm{day}$ & $\begin{array}{l}\text { Decrease in follicule-stimulating } \\
\text { hormone (FSH), luteinizing } \\
\text { hormone (LH), and testosterone }\end{array}$ & Issam et al 2009 \\
\hline \multirow{5}{*}{ In vitro } & $10^{-5} \mathrm{M}$ & $\begin{array}{l}\text { Antagonistic effects on } \mathrm{hER}_{\alpha} \\
\text { and } \mathrm{hER}_{\beta} \text { subtypes in } \mathrm{CHO}-1 \mathrm{~K} \\
\text { cells }\end{array}$ & Kojima et al. 2004 \\
\hline & $4.14 \times 10^{-6}$ & Estrogenic in $\mathrm{ER}_{\alpha} \mathrm{CV}-1$ cells & Du et al., 2010 \\
\hline & $1.32 \times 10^{-8}$ & $\begin{array}{l}\text { Anti-androgenic in MDA-kb2 } \\
\text { cells }\end{array}$ & Du et al., 2010 \\
\hline & $4.14 \times 10^{-9}$ & Antagonism at $\mathrm{TR}_{\beta} \mathrm{CV}-1$ cells & Du et al., 2010 \\
\hline & $10^{-7}-10^{-6}$ & Estrogenic in MCF-7 assay & Chen et al., 2002 \\
\hline \multicolumn{4}{|l|}{ Resmethrin } \\
\hline \multirow{2}{*}{ In vitro } & $10^{-4}-10^{-5} \mathrm{M}$ & $\begin{array}{l}\text { Weak competitor for androgen } \\
\text { binding sites in human skin } \\
\text { genital fibroblast cells }\end{array}$ & Eil and Nisula 1990 \\
\hline & $1-30 \mu \mathrm{M}$ & $\begin{array}{l}\text { No androgen antagonism in } \\
\text { CHO } 1 \mathrm{~K} \text { cells }\end{array}$ & Vinggaard et al. 2008 \\
\hline \multicolumn{4}{|l|}{ Cyfluthrin } \\
\hline \multirow[b]{2}{*}{ Mammals } & $16-54 \mathrm{mg} / \mathrm{kg}$ & $\begin{array}{l}\text { Reduction in sex accessory } \\
\text { tissue }\end{array}$ & Zhang et al., 2008 \\
\hline & $36 \mathrm{mg} / \mathrm{kg}$ & $\begin{array}{l}\text { Reduction in sex accessory } \\
\text { tissue }\end{array}$ & Zhang et al., 2008 \\
\hline \multirow{4}{*}{ In vitro } & $1.36 \times 10^{-6}$ & $\begin{array}{l}\text { Anti-estrogenic in } \mathrm{ER}_{\alpha} \mathrm{CV}-1 \\
\text { cells }\end{array}$ & Du et al., 2010 \\
\hline & $8.84 \times 10^{-8}$ & $\begin{array}{l}\text { Anti-androgenic in MDA-kb2 } \\
\text { cells }\end{array}$ & Du et al., 2010 \\
\hline & $5.39 \times 10^{-7}$ & Antagonism at $\mathrm{TR}_{\beta} \mathrm{CV}-1$ cells & Du et al., 2010 \\
\hline & $59 \mu \mathrm{M}, 84 \mu \mathrm{M}$ & Estrogenic and antiandrogenic & Kojima et al., 2004 \\
\hline \multicolumn{4}{|l|}{ Esfenvalerate } \\
\hline Fish & $4-148 \mathrm{mg} / \mathrm{kg}$ & $\begin{array}{l}\text { Decline in fecundity and } \\
\text { fertilization success }\end{array}$ & Werner et al., 2002 \\
\hline Mammals & $7.5-30 \mathrm{mg} / \mathrm{kg}$ & $\begin{array}{l}\text { Inhibited aggression in male } \\
\text { mice, }\end{array}$ & Meng et al., 2013 \\
\hline \multirow[t]{2}{*}{ In vitro } & $10^{-6}$ & $\begin{array}{l}\text { Anti-estrogenic in MCF-7 BUS } \\
\text { cells }\end{array}$ & Kim et al., 2004 \\
\hline & $59 \mu \mathrm{M}$ & Estrogenic in $\mathrm{hER}_{\alpha}(\mathrm{CHO}$ line $)$ & Kojima et al., 2004 \\
\hline \multicolumn{4}{|l|}{ Fenvalerate } \\
\hline \multirow{3}{*}{ In vitro } & $30 \mu \mathrm{M}$ & Estrogenic, anti-androgenic & Gary \& Wolff, 1998 \\
\hline & $0.37 \mathrm{mM}$ & $\begin{array}{l}\text { Anti-androgenic in AR- } \\
\text { mediated CV-1 reporter gene } \\
\text { assay }\end{array}$ & Sun et al., 2007 \\
\hline & $10^{-10}-10^{-6}$ & $\begin{array}{l}\text { Estrogenic in MCF-7 assay, ER } \\
\text { binding inhibition, induced ps } 2 \\
\text { gene expression }\end{array}$ & Chen et al., 2002 \\
\hline
\end{tabular}




\begin{tabular}{|c|c|c|c|}
\hline & $16.84,1.60 \mu \mathrm{M}$ & $\begin{array}{l}\text { Estrogenic activity on } \mathrm{hER}_{\alpha} \text { and } \\
\mathrm{rER}_{\alpha} \text { subtypes of } \mathrm{CV}-1 \text { cells }\end{array}$ & Sun et al., 2014 \\
\hline & $37 \mu \mathrm{M}, 69 \mu \mathrm{M}$ & $\begin{array}{l}\text { Estrogenic in } \mathrm{hER}_{\alpha} \text {, anti- } \\
\text { androgenic in } \mathrm{hAR} \text { (CHO line) }\end{array}$ & Kojima et al., 2004 \\
\hline & $1.80 \times 10^{-6}$ & Estrogenic at $\mathrm{ER}_{\alpha}$ in $\mathrm{CV}-1$ cells & Du et al., 2010 \\
\hline & $4.48 \times 10^{-7}$ & $\begin{array}{l}\text { Anti-androgenic in MDA-kb2 } \\
\text { cells }\end{array}$ & Du et al., 2010 \\
\hline & $2.17 \times 10^{-6}$ & $\begin{array}{l}\text { Antagonism at } \mathrm{TR}_{\beta} \text { in } \mathrm{CV}-1 \\
\text { cells }\end{array}$ & Du et al., 2010 \\
\hline & $10-30 \mu \mathrm{M}$ & $\begin{array}{l}\text { Induced cell proliferation and } \\
\text { expression of ps } 2 \text { in MCF-7 } \\
\text { cells }\end{array}$ & Go et al., 1999 \\
\hline Lambda-cyhal & & & \\
\hline & $5.8 \mathrm{mg} / \mathrm{L}$ & Decreased T3, T4, testosterone & $\begin{array}{l}\text { Saravanan et al., } \\
2009\end{array}$ \\
\hline Fish & $0.2-0.6 \mathrm{uL} / \mathrm{L}$ & $\begin{array}{l}\text { Decreased T3 and T4, increase } \\
\text { in serum thyroid-stimulating- } \\
\text { hormone (TSH) }\end{array}$ & Dey and Saha, 2014 \\
\hline & $20-40 \mathrm{mg} / \mathrm{kg}$ & Decreased T3, T4 & Ali et al., 2014 \\
\hline Mammals & $\begin{array}{l}0.2,0.4 \text {, and } 0.8 \\
\mathrm{mg} / \mathrm{kg} / \text { day }\end{array}$ & $\begin{array}{l}\text { Reduction in seminal vesicle } \\
\text { weight, reduced epididymal } \\
\text { sperm count, motility and } \\
\text { viability, an increase in of } \\
\text { abnormal sperm number, and } \\
\text { histopathological lesions in } \\
\text { testicular tissue }\end{array}$ & Alsarar et al, 2012 \\
\hline & $23.1-95.4 \mu \mathrm{M}$ & $\begin{array}{l}\text { Anti-androgenic in MDA-kb2 } \\
\text { cell line }\end{array}$ & Orton et al., 2011 \\
\hline & $3.34 \times 10^{-8}$ & Estrogenic at $\mathrm{ER}_{\alpha}$ in $\mathrm{CV}-1$ cells & Du et al., 2010 \\
\hline & $1.18 \times 10^{-6}$ & $\begin{array}{l}\text { Anti-androgenic in MDA-kb2 } \\
\text { cells }\end{array}$ & Du et al., 2010 \\
\hline & $3.34 \times 10^{-8}$ & $\begin{array}{l}\text { Antagonism at } \mathrm{TR}_{\beta} \text { in } \mathrm{CV}-1 \\
\text { cells }\end{array}$ & Du et al., 2010 \\
\hline In vitro & $10^{-9}-10^{-5}$ & $\begin{array}{l}\text { (-) LCT: MCF-7 cell } \\
\text { proliferation }(>\text { than }(+) \text { LCT or } \\
\text { racemic mixture), increased ps } 2 \\
\text { expression }\end{array}$ & Zhao et al., 2010 \\
\hline & $10^{-9}-10^{-5}$ & $\begin{array}{l}(+) \text { LCT: MCF-7 cell } \\
\text { proliferation, increased ps } 2 \\
\text { expression }\end{array}$ & Zhao et al., 2010 \\
\hline & $10^{-9}-10^{-5}$ & $\begin{array}{l}\text { LCT: MCF- } 7 \text { cell proliferation, } \\
\text { increased ps } 2 \text { expression }\end{array}$ & Zhao et al., 2010 \\
\hline Metabolites & & & \\
\hline & $10 \mu \mathrm{M}$ & $\begin{array}{l}\text { 3-PBA: anti-estrogenic in hER } \\
\text { and rER assays }\end{array}$ & Sun et al., 2014 \\
\hline In vitro & $1.21 \mathrm{mM}$ & $\begin{array}{l}\text { 3-PBA: anti-androgenic in AR- } \\
\text { mediated CV-1 reporter gene } \\
\text { assay }\end{array}$ & Sun et al., 2007 \\
\hline & $10^{-9}-10^{-5}$ & PBCOH: Estrogenic in MCF-7 & Jin et al., 2010 \\
\hline
\end{tabular}




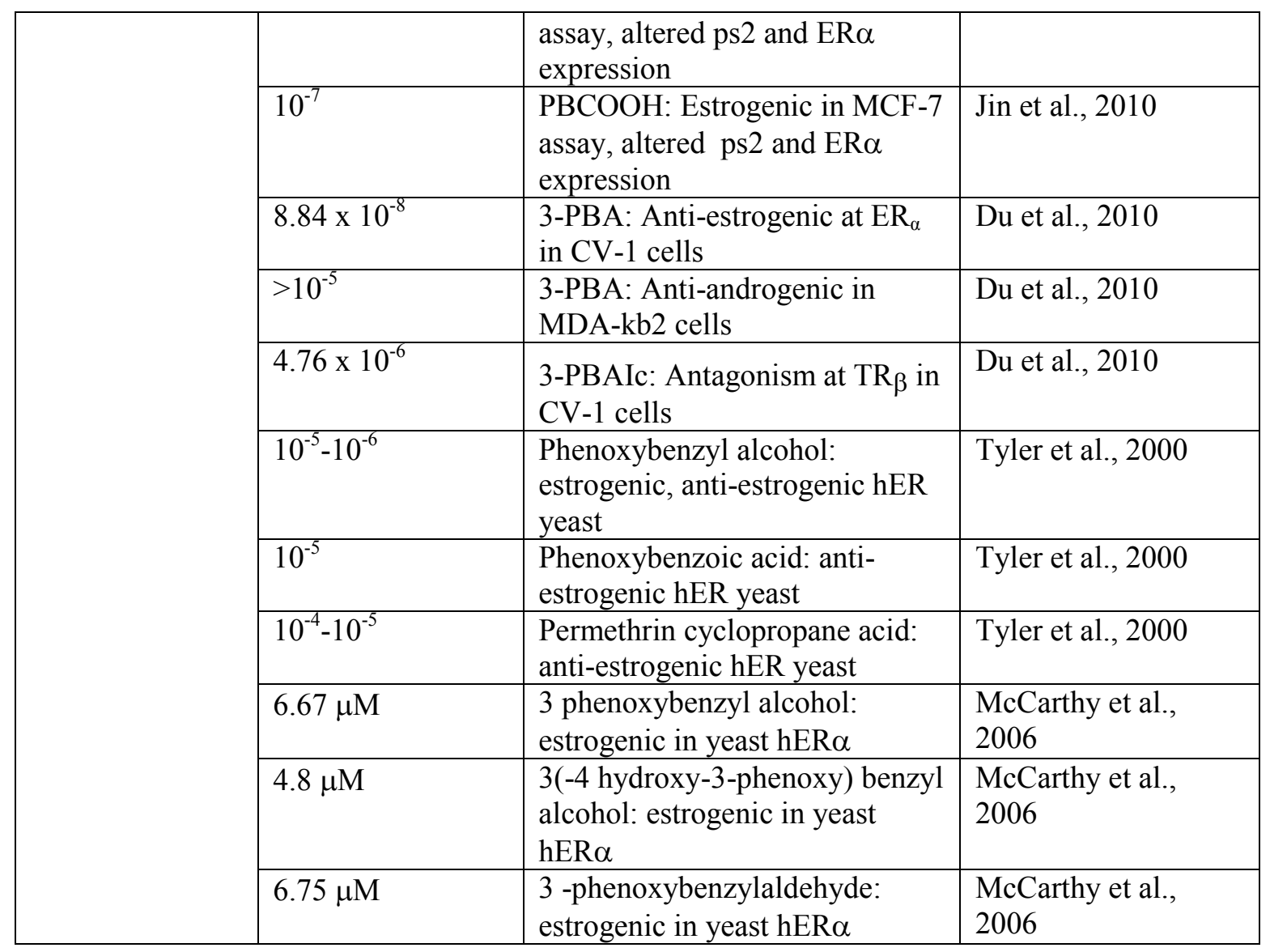

Assume pyrethroid referred to is racemic unless otherwise noted.

$\mathrm{E} 2$ = estradiol

hER = human estrogen receptor

$\mathrm{hAR}=$ human androgen receptor

$\mathrm{rER}=$ rat estrogen receptor

$\mathrm{CHO}=$ Chinese hamster ovary cell line

$\mathrm{CV}-1=$ monkey kidney cell line

JEG-3 = human placental choriocarcinoma cell line

MDA-kb2 = breast cancer cell line

MCF7 $=$ breast cancer cell line

3-PBA = 3-phenoxybenzoic acid

PBAIc $=3$-phenoxybenzyl alcohol

PBAId = 3-phenoxybenzaldehyde

PBAcid $=3$-phenoxybenzoic acid

$\mathrm{PBCOH}=3$-phenoxybenzoic alcohol

$\mathrm{PBCOOH}=3$-phenoxybenzoic acid 